\title{
NOTES FROM THE EDITOR
}

\section{RETIREMENT OF JOURNAL EDITOR}

I April the Journal will have a new Editor. After 5 years

I have elected to retire, feeling that someone younger and closer to clinical activity should take the helm.

It has been an eventful 5 years and the Journal has undergone significant changes. Some of these are:

- Associate Editors for the three subspecialties of cardiothoracic surgery, as well as for cardiothoracic physiology and support systems, have been added, allowing for greater expertise in editorial oversight.

- Editorials and commentaries have been added. In 1994 there were none. In 1999 there were 33.

- The review time and time to publication for full manuscripts has been reduced from 18 months to 9 months. Brief Communications appear in 5 to 6 months after receipt.

- Clinical Pathological Conferences have been added for General Thoracic Surgery to enhance the section's clinical relevance.

- Basic Science Reviews for cardiothoracic surgeons by well-established investigators are being published.

- Three additional sister publications are now sponsored by The American Association for Thoracic Surgery. The Seminars in Thoracic and Cardiovascular Surgery, The Operative Techniques in Thoracic and Cardiovascular Surgery, and the Pediatric Cardiac Surgery Annual. These publications complement the Journal in that they have superb clinical review articles featuring outstanding, in color, "how-to-do" descrip- tions of operations by acknowledged experts. These publications are edited by James Cox.

- The Journal is on time and appears each month in full text as part of the CTSNET, which is jointly owned by The American Association for Thoracic Surgery, the European Association for Cardiothoracic Surgery, and the Society of Thoracic Surgeons.

- The citation index of the Journal has risen to 3.068, and it has the highest such index of any journal in our field.

Many have contributed to these achievements. The Advisory Editorial Board has worked hard to give excellent reviews in a timely fashion. The Associate Editors, Ralph Damiano, L. Henry Edmunds, Richard Jonas, Nicholas T. Kouchoukos, D. Craig Miller, and Alexander Patterson, have brought their sections to a high level of expertise. Eugene Blackstone has seen to it that we all learned to conform to modern biostatistics, and those make the Journal one of the most respected in the world. David B. Campbell has led the way in bringing the Journal on-line. A special thank you goes to Cynthia Miller and her staff, who perhaps run one of the most efficient editorial offices anywhere. The publisher, Mosby, has been most cooperative in making the Journal more timely and better.

John A. Waldhausen, MD

Editor

12/1/103469

doi: $10.1067 / \mathrm{mtc} .2000 .103469$ 